О.Б. Дашинамжилов ${ }^{*}$

Статистические источники исследования этнической ассимиляции в 1959-1989 гг. ${ }^{* *}$

\author{
DOI: $10.31518 / 2618-9100-2019-4-14$ \\ УДК 316.347 (=512.31) “1959/1989”
}

Выходные данные для цитирования:

Дашинамжсилов О.Б. Статистические источники исследования этнической ассимиляции в 19591989 гг. // Исторический курьер. 2019.№ 4 (6). Статья 14. URL: http://istkurier.ru/data/2019/ ISTKURIER-2019-4-14.pdf

\author{
O.B. Dashinamzhilov
}

\section{Statistical resources for the research of ethnical assimilation in 1959-1989s}

\author{
DOI: 10.31518/2618-9100-2019-4-14
}

How to cite:

Dashinamzhilov O.B. Statistical resources for the research of ethnical assimilation in 1959-1989s // Historical Courier, 2019, \# 4 (6). Article 14. [Available online:] http://istkurier.ru/data/2019/ISTKURIER2019-4-14.pdf

Annotation. Statistical resources that are used for researching and revealing assimilation processes among various nationalities are analyzed in the work. The work is current because ethnical aspects of demographic development of Russia are not researched in progress. Therefore, historians, ethnologists, demographers, and also representatives of the government pay much attention to their results.

The order of the first statistical indexes, content of programming schedules, places of their current reservation, skills and ways for information collection, authenticity of the described resources are analyzed in the paper. Four points according to which the assessment can be made are revealed. Two of them can be included into All-Union Census and two others are found in the current population statistics. The materials that are collected according to answers to questions about a native language and also data about a share of mixed families are census. Information that is a basis for revealing a share of born children whose parents had another nationality is represented in the current population statistics. The data about a number of mixed ethnical marriages are another statistical resource.

It is proved that on the basis of the previous resources the objective assessment to assimilation processes among the majority of the peoples can be given. Applying them in complex is the best way to assess their dynamics and to see the depth of the process. The most interesting are such parts of the research where assimilation processes, dynamics of the language preference, international marriages are analyzed.

Keywords: historical demography; ethnodemography; resources; nationality; assimilation; Census; current population statistics.

The article has been received by the editor on 25.06.2019.

Full text of the article in Russian and references in English are available below.

Аннотация. В работе анализируются статистические источники, по которым можно изучить, выявить динамику и глубину ассимиляционных процессов у различных национальностей. Актуальность исследования обусловлена тем, что работы по изучению

\footnotetext{
* Дашинамжилов Одон Борисович, канд. ист. наук, научный сотрудник, Институт истории Сибирского отделения Российской академии наук (Новосибирск, Россия), e-mail: Odon@bk.ru

Dashiamzhilov Odon Borisovich, Candidate of Historical Sciences, Research Officer, Institute of History of the Siberian Branch of the Russian Academy of Science (Novosibirsk, Russia), e-mail: Odon@bk.ru

** Работа выполнена по программам фундаментальных научных исследований, определяемых Президиумом PAH.
} 
этнических аспектов демографического развития страны идут еще недостаточно активно. Именно поэтому их результаты вызывают повышенный интерес у историков, этнологов и демографов, а также у государственных органов власти.

В работе проанализированы порядок разработки первичных статистических показателей, содержание программных таблиц, места их современного хранения, приемы и способы сбора информации, достоверность описанных в работе источников. Выявлено четыре показателя, на основе которых возможно дать оценку ассимиляционным процессам. Два из них содержатся во Всесоюзных переписях и два - в текущем учете населения. К переписным относятся материалы, собранные по ответам на вопросы о родном языке, а также сведения о доле смешанных семей. В текущем учете населения представлена информация, на основе которой можно выявить долю рожденных детей, у которых отец был другой национальности. Еще одним статистическим источником являются сведения о числе межэтнических браков.

Доказано, что основе вышеназванных источников вполне возможно дать объективную оценку ассимиляции у большинства народов. Наилучшим способом является комплексное их использование, так как это позволит гораздо лучше оценить ее динамику и глубину. Большой интерес представляют разделы исследования, в которых на практике проанализированы ассимиляционные процессы, в том числе динамика языковых предпочтений, межнациональных браков.

Ключевые слова: историческая демография; этнодемография; источник; национальность; ассимиляция; перепись; текущий учет населения

$$
* * *
$$

В предметную область этнодемографии как науки входит изучение ассимиляции, так как она играла весомую роль в изменении численности национальностей. В свою очередь, это оказывало определенное влияние на этническую структуру и, косвенно, на естественное движение всего населения. На сегодняшний день этот процесс также идет активно, и это видно на примере многих народов, в том числе и нашей страны. Подходя к этой проблеме ученым-демографам необходимо знать, на какие цифровые данные можно опереться при ее изучении. В нашей статье мы попытаемся на примере бурятского этноса выявить и описать основные статистические источники ассимиляции.

Для начала необходимо определиться с терминами. Ассимиляция является одним из видов этнических процессов. Она проявляется в том, что группы людей, принадлежащие к сформированному этносу, оказавшись в тесном контакте с другим народом и его среде, воспринимают чужие язык и культуру. Постепенно, в последующих поколениях они сливаются с ним и причисляют себя к нему ${ }^{1}$. Некоторые статистические источники, которые на сегодняшний день находятся в архивах, могут способствовать углубленному и детальному анализу этого вопроса. Во Всесоюзных переписях и текущем учете населения существовали несколько систематизированных таблиц и разрабатываемых форм с данными, которые, тем не менее, нуждаются в определенной интерпретации.

Известно, что в ходе переписи происходили сбор, обобщение и публикация сведений обо всем, городском и сельском, мужском и женском населении, проживающем в заранее заданный момент времени в стране или ее части. Проведение Всесоюзных переписей осуществлялись под руководством Центрального статистического управления (ЦСУ) СССР. Советские переписи, которые проводились в послевоенный период, считаются точными источниками сведений о населении СССР. Так, в 1959 г. контрольными проверками было выявлено только 0,37 \% непереписанных лиц, и с каждой последующей переписью этот процент снижался. Несколько иначе обстояло дело с дальнейшим распределением населения по регионам Со-

\footnotetext{
${ }^{1}$ Демографический энциклопедический словарь. М.: Советская энциклопедия, 1985. С. 26.
} 
ветского Союза и категориями лиц, переписываемых в особом порядке, но это отдельная важная проблема, анализ которой не входит в задачу нашей работы.

В советское время в открытом доступе можно было обнаружить лишь небольшую часть переписных материалов, официально опубликованных в соответствующих многотомных изданиях. Более подробные сведения содержались в закрытых сборниках для служебного пользования (ДСП), которые выпускались ограниченными тиражами Центральным статистическим управлением и его региональными подразделениями. Основанная масса систематизированных таблиц со временем передавалась из облстатов в распоряжение государственных архивов.

Переписи собирали сведения о национальном и языковом составе населения. В программу каждой из них входил вопрос о родном языке, но часто он мог и не совпадать с национальностью, с которой ассоциировал себя опрашиваемый. Обычно, процессы ассимиляции шли активнее там, где высокой была доля лиц признавших родным язык другого народа. Динамику языковых предпочтений населения можно отследить и по официально опубликованным материалам переписей. Более подробную информацию с распределением людей по возрастным группам, не одним, а сразу нескольким языкам можно извлечь в основном только из систематизированных таблиц, которые хранятся в государственных архивах.

Например, согласно данным первой послевоенной переписи (1959 г.) у 4,9 \% всех бурят РСФСР родным являлся русский язык. Самой низкой эта доля была в Читинской области $(2,1 \%)$, наиболее высокой - в Иркутской $(7,0 \%)$, Бурятская АССР заняла промежуточное положение $(3,2 \%)^{2}$. Косвенно, это указывает на низкие темпы смены этнической самоидентификации у представителей этноса в конце 1950-х гг. У других народов РСФСР языковая ассимиляция шла быстрее. Например, среди татар эта доля составила 6,2\%, хакасов - 13,6 \%, карелов - 27,9\%.

От переписи к переписи доля бурят признавших русский язык в качестве родного последовательно росла. Так, в 1970 г. она увеличилась по РСФСР до 7,1 \%, а в 1979 г. - до $9,5 \%{ }^{3}$. К 1989 г. эта доля повысилась до $13,3 \%$, в том числе в Читинской области - до 7,4 \% Иркутской области - до 19,0\%, Республике Бурятия - до $10,6 \%{ }^{4}$. Позиции русского языка как средства бытового и межнационального общения постепенно укреплялись. У многих других народов отмечена схожая динамика. Так, у татар рассматриваемая доля выросла до $14,2 \%$, у хакасов - до $23,1 \%$, а у карелов она превысила половину численности этноса $51,2 \%$.

Как уже говорилось выше, более точные сведения о языковых предпочтениях можно получить, проанализировав переписные данные о распределении национальностей по возрасту и родному языку, которые стали собираться с 1970 г. Нумерация таблиц в переписях была различной: в 1970 г. - это 32с, в 1979 г. - 29c, в 1989 г. - вновь 32с. Информация в них представлена по всему, городскому и сельскому населению, мужчинам и женщинам. В основном эти таблицы находятся на хранении в фондах Российского государственного архива экономики (РГАЭ) и ведомственных архивах. Ситуация с областными (республиканскими) архивохранилищами обстоит сложнее, так как местные управления статистики далеко не всегда передавали в их распоряжение свои переписные материалы.

Из данных таблицы № 1 можно видеть, что доля населения, признавшего русский язык в качестве родного, от поколения к поколению последовательно росла. Так, например, если среди лиц старше 60 лет она составила всего 0,6 \%, то среди 40-49 летних - 1,7 \%, а 20-29

\footnotetext{
${ }^{2}$ Национальный состав населения РСФСР. По данным Всесоюзной переписи населения на 15 января 1959 года. (численность, расселение, городское и сельское население, соотношение мужчин и женщин, родной язык). М., 1961. (ДСП) С. 246.

${ }^{3}$ Национальный состав населения РСФСР по данным Всесоюзной переписи населения 1989 г. М., 1990. С. 148.

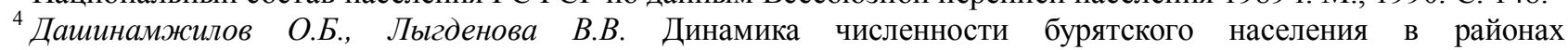
преимущественного расселения в 1959-2010 годах // Вестник НГУ. 2018. № 7. С. 129.
} 
летних - уже 6,9\%. У городских жителей языковая ассимиляция происходила быстрее. В возрастных группах горожан распределение оказалось следующим: среди тех, кому за 60 лет - 3,0 \%, 40-49 летних - 5,5\%, 20-29 летних - 12,5\% (все городское население - 15,0 \%). Быстрее всего этот процесс шел в крупных городах. Например, в Улан-Удэ удельный вес бурят признавших родным русский язык составил 16,3\%, в Чите - 18,9\%. Особенно высоким этот показатель был в Иркутской области, в том числе в самом Иркутске - 33,3 \%, Ангарске - 38,5 \%, Братске - 44,6 \%.

Таблица 1

\section{Распределение бурятского населения Бурятской АССР по родному языку в 1970 г.}

\begin{tabular}{|l|c|c|}
\hline \multicolumn{1}{|c|}{ Возраст } & Численность населения & $\begin{array}{c}\text { в т. ч. с русским родным } \\
\text { языком }\end{array}$ \\
\hline Всего & 178660 & 8811 \\
\hline $7-19$ & 59716 & 4190 \\
\hline $20-29$ & 21350 & 1473 \\
\hline $30-39$ & 21021 & 806 \\
\hline $40-49$ & 16257 & 283 \\
\hline $50-59$ & 13325 & 183 \\
\hline старше 60 лет & 16188 & 92 \\
\hline
\end{tabular}

* Распределение населения основных национальностей по полу, возрасту, языку, образованию и состоянию в браке по данным Всесоюзной переписи населения 1970 г. по Бурятской АССР. (таблицы 31с, 32c и 33c). М., 1971 (ДСП). С. 41.

В сельской местности языковая ассимиляция шла медленнее, но и там эта тенденция становилась все более заметной (все сельское население республики - 1,8 \%). В 1970 г. среди 60 летних и старше из 13,5 тыс. человек только 11 признали родным русский язык, среди 4049 летних - 80 человек (из 12,5 тыс.), 20-29 летних - уже 2,8 \% (из 12,4 тыс.).

Доля мононациональных семей стала еще одним показателем, который можно высчитать на основе систематизированных таблиц Всесоюзных переписей. Удельный вес последних в Советском Союзе постепенно уменьшался. Они считалась таковыми, если все члены семьи относились к одной национальности. Так, в 1979 г. доля бурят живших в мононациональных семьях по отношению ко всему бурятскому населению составила 81,8 \%, в 1989 г. - 80,9 \%. Кроме систематизированных таблиц материал для таких расчетов можно найти в официально опубликованных статистических сборниках, изданных в перестроечный период 5 .

Весьма любопытный материал для изучения ассимиляции дает текущий учет населения. Статистические органы получали сведения о распределении родившихся по очередности рождения и возрасту матери, по возрасту отца и матери, по источнику средств существования, уровню образования и национальности матери; о распределении умерших по полу и возрасту, источнику средств существования, образованию, национальности и прочее. Детальная информация собиралась о браках и разводах. Большая часть форм текущего учета со временем передавалась в местные архивы.

К началу 1960-х гг. текущий учет населения был неплохо отлажен. Количество незарегистрированных родившихся и умерших по сравнению с предшествующем историческим периодом значительно сократилось. Дело в том, что, например, с регистрацией актов гражданского состояния была связана выдача хлебных карточек, городские кладбища могли не проводить захоронения без фиксации смерти в органах ЗАГС и т. д. ${ }^{6}$ Судя по некоторым годам, недоучет составлял в среднем по регионам не более 2,0-2,5\%. При этом

\footnotetext{
${ }^{5}$ См. напр.: Некоторые показатели, характеризующие национальный состав населения РСФСР по данным Всесоюзной переписи населения 1989 года. М., 1990. Том 1: Пол, возраст, брачное и семейное состояние населения отдельных национальностей. С. 183-186.

${ }^{6}$ См. напр.: Алексеев B.В., Исупов В.А. Население Сибири в годы Великой Отечественной войны. Новосибирск: Наука, 1986. С. 9.
} 
часть его выявлялась в ходе ежегодных проверок.

Достоверно установлено, что в многонациональных семьях ассимиляция шла активнее. По достижению определенного возраста дети из таких семей могли по своему усмотрению выбрать национальность одного из родителей. Существует статистический источник, на основе которого можно дать косвенную оценку количеству таких детей. Это форма № 3 текущего учета населения - «Сведения о родившихся и умерших по национальностям».

Данные к ней собирались как по всему населению, так и по городским поселениям и сельской местности. Использование такого источника ограничивает количество национальностей, которые попадали в разработку. В обязательном порядке собиралась информация по семи крупнейшим народам СССР - русским, украинцам, белорусам, казахам, армянам, татарам и евреям. Кроме них, в этой форме могли присутствовать в зависимости от области или республики дополнительно еще два или более этносов. Национальность новорожденного определялась по этнической принадлежности матери.

Для нас важно то, что из общего количества родившихся отдельной строкой выделялись дети, у которых отец был иной национальности. Следует иметь в виду, что такой источник точнее отражал ассимиляционные процессы у представителей этносов, проживавших в «своих» административных образованиях - союзных и автономных республиках, автономных областях и округах. Если для оценки ассимиляции собирать информацию архивов тех областей (республик), которые не являлись территориями преимущественного расселения народа, то появляется риск сделать поспешные и неправильные выводы (например, по украинцам в РСФСР или татарам в Московской области). Это вызвано тем, что в других регионах доля мононациональных семей а, следовательно, рожденных у них детей значительно сокращается.

По материалам текущей статистики за период между Всесоюзными переписями 1959 и 1970 гг. в Бурятской АССР только у 0,7 \% от всех рожденных бурятскими женщинами детей отец принадлежал к другой национальности. Из этого логично вытекает вывод о том, что ассимиляция шла тогда очень медленно. Она несколько ускорилась в следующий межпереписной период (1970-1979 гг.), но по-прежнему имела низкие темпы (2,3\%). Отсутствие всех данных в архивах не позволило нам сделать такой же анализ за 1980-е гг. Но, судя по всему, доля детей, у которых отец относился к другой национальности, продолжала повышаться (1988 г. - 7,0\%) .

Если исходить из статистических материалов соседних регионов, то в Читинской области этот процесс шел почти с такой же скоростью, что и в Бурятии, а в Иркутской области интенсивнее. Так, в 1960 г. в Читинской области среди рожденных бурятскими женщинами детей только у девяти $(0,6 \%)$ отец был другой национальности, в 1971 г. - у 2,4 \%, в 1979 5,6 \%, в 1987 г. - у 8,2 \% ${ }^{8}$. В Иркутской области в 1960 г. - у 1,7 \%, 1971 г. - 8,0 \%, в 1987 г. у $14,8 \%{ }^{9}$.

Необходимо сказать о том, что в Иркутской области восстановить непрерывный ряд статистических данных не позволяет отсутствие сведений текущего учета за ряд лет, а в Читинской области сомнение вызывает правильность заполнения соответствующих форм изза чрезмерного разброса показателей. Вероятно, такая же проблема ждет других исследователей, которые захотят привлечь аналогичные данные по другим этносам.

Статистические сведения по городским поселениям и сельской местности подтверждают различия в скорости ассимиляции. Так, например, в городах Бурятии было больше тех, у кого отец был другой национальности: 1960-е гг. - 2,1\%, в 1970-е гг. - 4,8\%, в 1988 г. - 9,0 \%; в сельской местности, наоборот, меньше $(0,4 \%, 1,5 \%, 5,8 \%)$.

\footnotetext{
${ }^{7}$ Государственный архив Республики Бурятия (ГАРБ). Ф. Р-196. Оп. 1/8. Д. 186. Л. 8.

${ }^{8}$ Государственный архив Забайкальского края (ГАЗК). Ф. Р-1645. Оп. 5. Д. 352. Л. 17об; Д. 590а, Л. 29об; Д. 816. Л. 55об; Д. 1164. Л. 40об.

${ }^{9}$ Государственный архив Иркутской области (ГАИО). Ф. 2679. Оп. 7. Д. 70. Л. 51об; Д. 102. Л. 65об; Д. 138, 43 об.
} 
Ценными источниками являются формы, которые содержат сведения о межнациональных браках. Такие данные не разрабатывались регулярно, а только за прилегающие к переписям годы, например, в 1979 г. это форма № 7-б. В ней отдельно указывалась статистика по мужчинам и женщинам, а численность национальностей также была небольшой. Данные по русским, украинцам и белорусам разрабатывались каждым областным управлением статистики, которые могли в зависимости от региона добавлять еще несколько этносов. К сожалению, в архивах Читинской и Иркутской областей подобная статистика по бурятам за 1979 г. отсутствует и, вероятно, не разрабатывалась. Данные по Бурятской АССР показывают, что среди заключенных бурятскими мужчинами браков супругой в 92,8 \% являлась женщинабурятка. У последних супруг той же национальности был в $91,1 \%$ случаев ${ }^{10}$. Эта доля в сравнении с другими этносами была высокой.

Итак, в работе показано, что на основе вышеназванных статистических источников вполне возможно дать оценку тенденциям ассимиляции у большинства национальностей. Наилучшим способом является комплексное их использование, так как это позволит гораздо лучше оценить динамику и глубину рассматриваемого процесса.

\section{Лumepamypa}

Алексеев В.В., Исупов В.А. Население Сибири в годы Великой Отечественной войны. Новосибирск: Наука, 1986. 232 с.

Дашинамжилов О.Б., Лыгденова В.В. Динамика численности бурятского населения в районах преимущественного расселения в 1959-2010 годах // Вестник НГУ. 2018. № 7. C. 121-134.

Демографический энциклопедический словарь. М.: Советская энциклопедия, 1985. 608 с.

\section{References}

Alekseev V.V., Isupov V.A. Naselenie Sibiri v gody Velikoy Otechestvennoy voyni [Population of Siberia during the Second World War]. Novosibirsk: Nauka, 1986. 232 p.

Dashinamzhilov O.B., Lygdenova V.V. Dynamics of Buryats population in the regions of major settlement in 1959-2010s. // Vestnik NGU, 2018, № 7. P. 121-134.

Demograficheskiy enciklopedicheskiy slovar [Demographic Encyclopedia] // Sovetskaya enciklopediya. Moscow, 1985. 608 p.

Статья поступила в редакичию 25.06.2019 г.

${ }^{10}$ ГАРБ. Ф. Р-196. Оп. 1/8. Д. 77. Л. 127-127об. 